\title{
Eating Disorder Disease - Potential Causes and Physical Complications
}

\author{
Shreyas Saride ${ }^{1}$, Esha Kanna1, Vincent Aroulmoji², \\ Rathinavel Thirumalaisamy ${ }^{3}$, Riaz Khan ${ }^{4}$
}

${ }^{1}$ School of Behavioral and Brain Sciences, The University of Texas at Dallas, 800 W Campbell Rd, Richardson, TX 75080, United States of America (USA)

${ }^{2}$ Centre for Research \& Development, Mahendra Engineering College (Autonomous),

Mallasamudram, Namakkal (Dt.) - 637 503, Tamil Nadu, India

${ }^{3}$ Department of Biotechnology, Sona College of Arts and Science, Salem-636 005, Tamilnadu, India

${ }^{4}$ Rumsey, Old Bath Road, Sonning, Berkshire, RG4 6TA, England, United Kingdom (UK)

\begin{abstract}
The purpose of this review is to create awareness about Eating Disorders (ED) disease to the sufferers, their families, and the society in general. The disease threatens the health of millions of young girls aged roughly between 14 to 28 years and also some boys. The review will deal with the following topics related to Eating Disorders (ED): Hunger and why we feel hungry; discuss the causes of eating disorder (ED), which comprises of anorexia nervosa (AN), bulimia Nervosa (BN) and binge eating disorder (BED); describe the ED's relationship with psychological issues; throwing light on its relationship with physical complications; the availability of drugs for the treatment of ED; a set of guidelines for hospitalization of ED patients by the Society for Adolescent Medicine; elaboration of the important question of prevention of disease; the position of ED in India, the influx of social media, social and cultural values; requirement of serious attention to obtain a realistic picture of the ED issue. Finally, quarantine and selfisolation have undoubtedly caused negative consequences for one's mental health due to separation from loved ones, loss of freedom, loss of income, and increased boredom.
\end{abstract}

KEYWORDS: Eating disorder, mortality, hunger, anorexia nervosa, Bulimia Nervosa, Binge Eating Disorder

https://doi.org/10.29294/IJASE.8.2.2022.2283-2287

C2022 Mahendrapublications.com, All rights reserved

\section{INTRODUCTION}

Eating Disorders (ED) are classified as acute psychiatric and psychological illnesses, affecting at least nine percent of the world's population. Eating disorders can manifest themselves in different ways, such as dietary restrictions and negative self-images. These feelings of body dysmorphia are further instilled by unrealistic body images portrayed on social media platforms. With the increased level of social media exposure for children, the causes of eating disorders have been and will continue to rise in the coming years. Eating disorders impact people regardless of age, race, or gender; however, the highest number of reported cases for these disorders primarily lies among females aged 12 to 25 years old [1]. These disorders can lead to various health issues, including kidney and cardiac complications, the onset of psychological disorders, and in extreme cases, death. Eating disorders are ranked as the second leading cause of death among mental disorders, potentially because only $23 \%$ of those diagnosed with eating disorders receive proper treatment [2]. Forming the appropriate treatment plan for these patients is challenging not only due to the physical and mental aspects of these disorders but also the psychological barriers that may prevent patients from committing to their recovery process. As the prevalence of these disorders continues to increase worldwide, an emphasis on research and education on eating disorders is essential to inform and support people all over the world.

\section{HOW/WHY DO YOU FEEL HUNGER/HUNGRY?:}

Hunger is classified as a sensation that prompts one's body to eat and can present itself in various ways based on each individual. Hunger is primarily controlled by the hypothalamus, glucose levels in the bloodstream, the emptiness of the stomach and other digestive organs, and other hormones (i.e., ghrelin) in the body [3]. For many patients with eating disorders, the feeling of hunger is distorted, causing irregular and unsafe eating habits. Negative perceptions of their bodies may lead these individuals to ignore their body's

\begin{tabular}{rcr}
${ }^{*}$ Corresponding Author: Sshreyas2002@gmail.com \\
Received: 10.01 .2022 & Accepted: 15.02 .2022 & Published on: 22.02 .2022 \\
\hline
\end{tabular}

Shreyas Saride et al., 
signal to eat, causing them not to receive the necessary nutrients to carry out their daily

\section{INTRODUCING SPECIFIC DISEASES/DISORDERS}

Specific Eating Disorders: [4] activities and take care of their body's organ systems.

\begin{tabular}{|c|l|}
\hline Eating Disorder & \multicolumn{1}{c|}{ Characteristics } \\
\hline Anorexia Nervosa (AN) & $\begin{array}{l}\text { 15\% or more are below the ideal body weight } \\
\text { Fear of weight gain } \\
\text { Severe body image disturbance } \\
\text { In post-marechal females, absence of the } \\
\text { menstrual cycle, or amenorrhea }\end{array}$ \\
\hline Bulimia Nervosa (BN) & $\begin{array}{l}\text { Episodes of binge eating due to a loss of control } \\
\text { Binge eating followed by compensatory behavior } \\
\text { of the purging type } \\
\text { Binges and resulting compensatory behavior } \\
\text { occurring for a minimum two times per week for } \\
\text { three months } \\
\text { Dissatisfaction with body shape and weight }\end{array}$ \\
\hline $\begin{array}{c}\text { Binge Eating Disorder } \\
\text { (BED) }\end{array}$ & $\begin{array}{l}\text { Eating more rapidly than normal } \\
\text { Eating until uncomfortably full } \\
\text { Eating large amounts of food when physically } \\
\text { hungry } \\
\text { Eating alone because of embarrassment } \\
\text { Feeling disgusted, depressed, or very guilty after } \\
\text { overeating }\end{array}$ \\
\hline
\end{tabular}

\section{POTENTIAL CAUSES}

Eating disorders, in most cases, have been caused by a combination of biological and social issues. According to Mayo Clinic, a family's medical history with eating disorders plays a role in one's genetic predisposition to developing an eating disorder. These genetic factors account for almost $40 \%$ to $60 \%$ of eating disorders due to their role in aspects such as abnormal hormone levels and a person's body shape or structure [5]. These biological factors coupled with the similar environments that families live in can be attributed to the probability of family members being diagnosed with an eating disorder.

In addition to the biological basis of eating disorders, the pressures that society has placed on its members to look and act in a certain manner have also caused a surge in the number of individuals diagnosed with an eating disorder. In the age of social media, the idea of attaining the ideal body shape has continued to plague the minds of young adults and has caused people to seek unhealthy methods to lose weight and sculpt their bodies. With the increased access to social media at young age, children are exposed to unrealistic body standards when their brains are incredibly malleable and experiences can significantly impact their lives. Additionally, the lack of regulation on these social media platforms can lead to an influx of negative comments about an individual's body image and personal life, increasing the likelihood of developing mental health issues such as an eating disorder [6].

\section{RELATION TO PSYCHOLOGICAL ISSUES}

In many cases, eating disorders have been found to co-occur with other mental health disorders. One study aimed at determining the effectiveness of concurrently treating both eating disorders and posttraumatic stress disorders proved to be statistically significant and successfully exhibited a relationship between both diseases [2]. These results can help us create more impactful treatments for these disorders, as we understand more facets of the condition.

Another study looks at the co-morbidity rate and treatment plans for patients with eating disorders and bipolar disorder [7]. This study 
states that anxiety, alcohol abuse, drug use, and depressive conditions are co-occurring symptoms in eating disorders and bipolar disorder. Although more research needs to be done, the co-morbidity of bipolar disorder with eating disorders could represent another subset of the disease that can be used to understand the condition better and formulate treatment.

\section{RELATION TO PHYSICAL COMPLICATIONS}

Especially with anorexia nervosa, damage to the patient's heart is one of the most common reasons for hospitalization. Patients with anorexia lack essential nutrients, forcing their bodies to conserve energy and reduce output. These changes can cause the heart to shrink and get weaker, inhibiting the circulation of critical blood and nutrients to other areas of the body, mirroring a positive feedback loop. As mentioned, anorexia can lead to a weaker heart causing bradycardia (abnormally slow heartbeat), low blood pressure, and deteriorating heart muscles [8].

Eating disorders can also be linked to dehydration, the most common cause of acute kidney injury (AKI). Purging behaviors along with laxative and diuretic usage depletes the kidney's volume and could lead to AKI. The kidneys will respond to this change by attempting to retain hydration and stabilize blood pressure to maintain homeostasis. However, when volume loss becomes frequent, the kidneys will no longer be able to cope with the damage. Although some patients may recover full kidney function, others may have permanent damage that could develop into chronic kidney disease [9].

\section{DRUGS AND TREATMENTS AVAILABLE}

Treatments for patients diagnosed with eating disorders can be difficult to formulate, because they have both physical and mental symptoms. Primarily, treatments must ensure that their dietary needs are met regardless of psychological barriers. For many with anorexia nervosa, they are unable to successfully eat a single meal without feeling physically and mentally ill. On the other hand, those with bulimia nervosa and binge eating disorder may have difficulty limiting their intake of food throughout the day. These obstacles require great levels of mental strength to overcome, especially if their distress in terms of body image has controlled their lives for months or years. Professionals such as psychologists or therapists can help patients overcome these mental blockades as they aim to decrease their patients' feelings of body dysmorphia and fears of weight gain. However, if these treatments do not work for patients, there are only a few pharmacological treatments approved and available for those diagnosed with eating disorders. Therefore, understanding the causes, instances of co-morbidity, and broad range of symptoms pertaining to eating disorders can help create personalized and effective treatments for patients [4].

\section{Pharmacological Treatments: [4]}

\begin{tabular}{|c|c|}
\hline $\begin{array}{l}\text { Eating } \\
\text { Disorder }\end{array}$ & Pharmacological Treatment \\
\hline $\begin{array}{c}\text { Anorexia } \\
\text { Nervosa }\end{array}$ & $\begin{array}{l}\text { Currently, there are no } \\
\text { medicines that have been shown } \\
\text { to effectively treat anorexia } \\
\text { nervosa. } \\
\text { Anxiolytic medications can be } \\
\text { used to help patients feeling } \\
\text { anxious prior to eating. } \\
\text { According to the American } \\
\text { Psychiatric Association, } \\
\text { psychotropic medications can be } \\
\text { considered to prevent a "relapse } \\
\text { in the weight restored patients } \\
\text { or to treat depression or } \\
\text { obsessive-compulsive disorder" }\end{array}$ \\
\hline $\begin{array}{l}\text { Bulimia } \\
\text { Nervosa }\end{array}$ & $\begin{array}{l}\text { Fluoxetine: (i.e. Prozac) } \\
\text { - } \quad \text { Mechanism of Action: } \\
\text { Selectively inhibits } \\
\text { serotonin reuptake } \\
\text { - } \quad \text { Dosing: } 60 \text { mg QAM } \\
\text { Tricyclic antidepressants: (i.e. } \\
\text { desipramine, imipramine, and } \\
\text { amitriptyline) } \\
\text { - Mechanism of Action: } \\
\text { inhibits norepinephrine and } \\
\text { serotonin reuptake } \\
\text { Anticonvulsant - Topiramate: } \\
\text { (i.e.Topomax) } \\
\text { - Mechanism of Action: } \\
\text { blocks voltage-dependent } \\
\text { sodium channels; augments } \\
\text { GABA activity; antagonizes } \\
\text { glutamate receptors; } \\
\text { inhibits carbonic anhydrase } \\
\text { Antiemetic medication - } \\
\text { Ondansetron: (i.e. Zofran) } \\
\text { - Mechanism of Action: } \\
\text { selectively antagonizes } \\
\text { serotonin 5-HT3 receptors }\end{array}$ \\
\hline $\begin{array}{l}\text { Binge Eating } \\
\text { Disorder }\end{array}$ & $\begin{array}{l}\text { Topiramate (most effective) } \\
\text { Selective serotonin reuptake } \\
\text { inhibitors } \\
\text { Antiepileptics } \\
\text { Appetite suppressants }\end{array}$ \\
\hline
\end{tabular}




\section{HOSPITALIZATION FOR EATING DISORDERS}

According to the guidelines by the Society for Adolescent Medicine, the criteria listed below call for hospitalization due to eating disorders [10].

- Malnutrition (less than 75\% of average body weight for age, sex, and height)

- Dehydration

- Electrolyte disturbances

- Cardiac Dysrhythmia

- Physiological Instability

- Limited growth and development

- Failure of outpatient treatment

- Acute food refusal

- Uncontrollable binging and purging

- An acute medical complication of malnutrition

- Acute psychiatric emergencies

- A comorbid diagnosis that interferes with the treatment of eating disorders

\section{PREVENTION OF EATING DISORDERS}

The complexity of the subject of eating disorders is due to the influence of social stressors and physiological phenomena such as genetic predispositions and the impact of social, cultural, and interactional factors on the brain. Based on these factors, Casa Palmera, a well-known holisticbased Institution, has posted a set of eight pieces of advice to help with eating disorders [11].

1. Believe that you are more than just your body figure. A particular diet, body weight, or size will not automatically lead you to happiness and fulfillment.

2. Learn everything you can about anorexia nervosa, bulimia nervosa, binge eating disorder, and other types of eating disorders. Genuine awareness of the eating disorder (ED) is essential to recognize and identify the signs of potential eating disorders in yourself and others.

3. Challenge the false notion that gaining weight is not socially acceptable, if this thought persists, try to seek cognitive behavioral therapy.

4. Avoid categorizing foods as "good/safe" Vs "bad/dangerous", one needs to eat a balanced diet consisting of a variety of foods.

5. Do not judge others or yourself based on body shape or weight.

6. Be a critical viewer of the media and its messages about self-esteem and body image.
7. Choose to value yourself based on your goals, accomplishments, talents, and character. When you think about your body, do not focus on how it looks but on what it can do.

8. Finally, if you think someone has an eating disorder, express your concerns in a caring and forthright manner. Encourage the person to seek professional help. If you have an eating disorder, do the same in order to regain control over your life.

\section{ROLE OF EATING DISORDERS IN INDIA}

According to various studies on the prevalence of eating disorders in Asian and Arab countries such as India, eating disorders appear to be side effects of globalization. The influx of social media has made unnatural and unrealistic ideals on body shape easily accessible, putting anyone who views these resources at risk. Data has also proven that certain Asian cultural norms may be a factor in the development of eating disorders. In most Asian cultures, there is a heavy emphasis on family and society, usually taking focus away from critical personal issues such as mental health [12].There is still very little known about eating disorders in India. As the prominence of these disorders starts to rise, research is still needed to determine the best way to prevent these disorders and formulate effective treatment options.

\section{COVID AND MENTAL HEALTH DISORDERS:}

Since COVID-19 pandemic started in November 2019, the social landscape has been altered dramatically. Although concrete statistics have yet to be released due to the ongoing pandemic, there is much speculation regarding the growth of mental health disorders. Quarantine and selfisolation can undoubtedly negatively affect an individual's mental health due to the separation from loved ones, loss of social freedom, and possible loss of jobs. Efforts to combat the pandemic could be particularly condemning for children and teenagers who are already more susceptible to mental health and eating disorders [13]. Children in these quarantined environments can experience "anxiety, distress, social isolation, and an abusive environment that can have short or long term effects on their mental health"[14]. The pandemic could also be extremely damaging to children who have lost their parents to the fatal virus or whose socioeconomic status has deteriorated significantly. As the pandemic rages on, it is crucial to look out not only for yourself but also for others who may need help. 


\section{CONCLUSION}

Genuine awareness and understanding of the eating disorders disease adversely affecting the mental health of millions of our young girls and some boys, is of paramount importance. Its treatments are frequently multi-faceted, commonly involving psychotherapy and pharmacotherapy. Additionally, complementary research is required in order to fully understand these eating disorders and how they manifest themselves in different countries. National and international health organizations of both developing and developed countries must seriously address this issue and act upon with urgency to eliminate this debilitating disease, before it reaches a pandemic level with disastrous consequences.

\section{REFERENCES}

[1] National Association of Anorexia Nervosa and Associated Disorders. 2021. Eating disorder statistics.

https://anad.org/get-informed/abouteating-disorders/eating-disorders-

statistics/

[2] National Eating Disorders Association. Avoidant restrictive food intake disorder (ARFID).

https://www.nationaleatingdisorders.org/l earn/by-eating-disorder/arfid

[3] Zelman, K. M., \& LD. 2005. Am I really hungry?

https://www.webmd.com/diet/features/re ally-hungry\#1

[4] Gorla, K., Mathews, M. 2005. Pharmacological treatment of eating disorders. Psychiatry (Edgmont). Jun; 2(6): 43-48.

[5] Trace, S. E., Baker, J. H., Peñas-Lledó, E., Bulik, C. M. 2013. The genetics of eating disorders. Annual review of clinical psychology, 9, 589-620.
[6] Gleissner, G. 2017. Social media and its effect on eating disorders.

www.huffpost.com/entry/social-mediaand-its-effect-on-eatingdisorders_b_591343bce4b0e3bb894d5caa

[7] McElroy, S.L., Kotwal, R. and Keck, P.E., Jr 2006, Comorbidity of eating disorders with bipolar disorder and treatment implications. Bipolar Disorders, 8: 686-695.

[8] Northwestern Medicine. 2016. How anorexia impacts your heart. https://www.nm.org/healthbeat/healthytips/anorexia-and-your-heart

[9] Rosen, E. 2019. Kidney failure and eating disorders: Acute kidney injury vs. chronic kidney disease - Gaudiani clinic. Gaudiani Clinic.

https://www.gaudianiclinic.com/gaudianiclinic-blog/2019/11/6/kidney-failure-andeating-disorders-acute-kidney-injury-vschronic-kidney-disease

[10] Golden NH. Katzman DK. Kreipe RE. Stevens SL. Sawyer SM. Rees J. Nicholls D. Rome ES.2003. Eating disorders in adolescents: position paper of the Society for Adolescent Medicine. Journal of Adolescent Health. 33(6): 496-503.

[11] Casa Palmera. 2010. 8 ways to prevent eating disorders (Plus 5 recommendations for parents).

https://casapalmera.com/blog/8-ways-toprevent-eating-disorders/

[12] Motwani, S., Karia, S., Mandalia, B., \& Desousa, A. 2021. Eating Disorders in India: An Overview. Annals of Psychiatry 5(1) 1217.

[13] Nayar, R. K. 2020. COVID 19 and its mental health-consequences.

https://www.tandfonline.com/doi/full/10. $1080 / 09638237.2020 .1757052$ ?scroll=top \&needAccess $=$ true

[14] Javed, B., Sarwer, A., Soto, E. B., \& Mashwani, Z. U. 2020. The coronavirus (COVID-19) pandemic's impact on mental health. Int J Health Plann Manage. 2020 Jun 22, PMCID: PMC7361582 